\title{
Ruptured Retina Artery Macroaneurysm Presenting with Recurrent Vitreous Haemorrhage: A case report
}

\author{
TS Oluleye, OA Taiwo
}

Retina and Vitreous Unit, Department of Ophthalmology, University College Hospital Ibadan

\section{SUMMARY}

A 74-year-old hypertensive presented with recurrent vitreous haemorrhage. Examination showed a ruptured retinal arterial macroaneurysm. Control of systemic hypertension was associated with resolution. Risk factors and management are discussed. Ruptured retinal arterial macroaneurysm should be considered in elderly hypertensive patients presenting with vitreous haemorrhage.

Keywords: retinal arterial macroaneurysm; vitreous haemorrhage; systemic hypertension

\section{CASE REPORT}

Patient KO, a 74-year-old woman was referred to the Retina Clinic of the University College Hospital, Ibadan on account of bleeding into LE. The presenting episode occurred suddenly and was painless about 2 months before presentation. She had 2 previous episodes of blurred vision that recovered gradually after 3 months. She had no antecedent trauma and no history of bleeding diathesis. She is a known hypertensive with poor treatment compliance. Systemic examination revealed blood pressure of 190/90 $\mathrm{mmHg}$. Results of other systemic examinations were normal. Ocular examination revealed corrected visual acuity of $6 / 5$ in the right eye and $6 / 9$ in the left eye. The anterior and posterior segments of the right eye were normal. The anterior segment of the left eye was normal, but funduscopy revealed hazy media from vitreous haemorrhage and a fusiform dilatation of the $2^{\text {nd }}$ order arteriole with surrounding subretinal haemorrhage (see figure 1). An assessment of ruptured retinal artery macroaneurysm was made. The patient was referred to the physician for control of systemic hypertension, and was instructed to sleep with extra pillows for head elevation to aid settling of the vitreous haemorrhage. Follow-up visits showed clearance of the vitreous haemorrhage, with improvement of vision to $6 / 6$.

\section{DISCUSSION}

Retinal artery macroaneurysm is a focal dilatation in the retina arteriole occurring in the $1^{\text {st }}$ to $3^{\text {rd }}$ order of arteriolar bifurcation. ${ }^{1}$ The most common site is the second order of the superotemporal arteriolar bifurcation ${ }^{2}$ (figure 2). This patient's aneurysm was located in the second order of the supero-temporal arteriole.

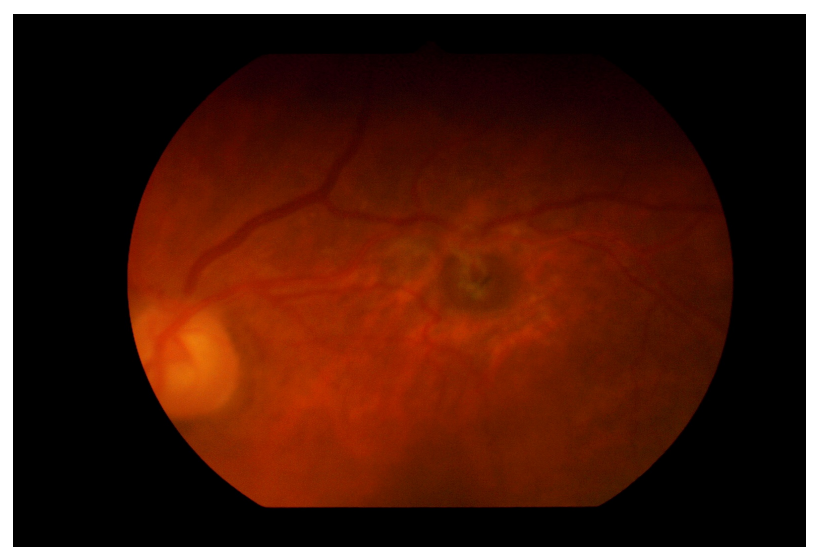

Figure 1. Fundus photo of patient $\mathrm{KO}$ with retina artery macroaneurysm at the second order superotemporal arteriole with surrounding subretinal haemorrhage.

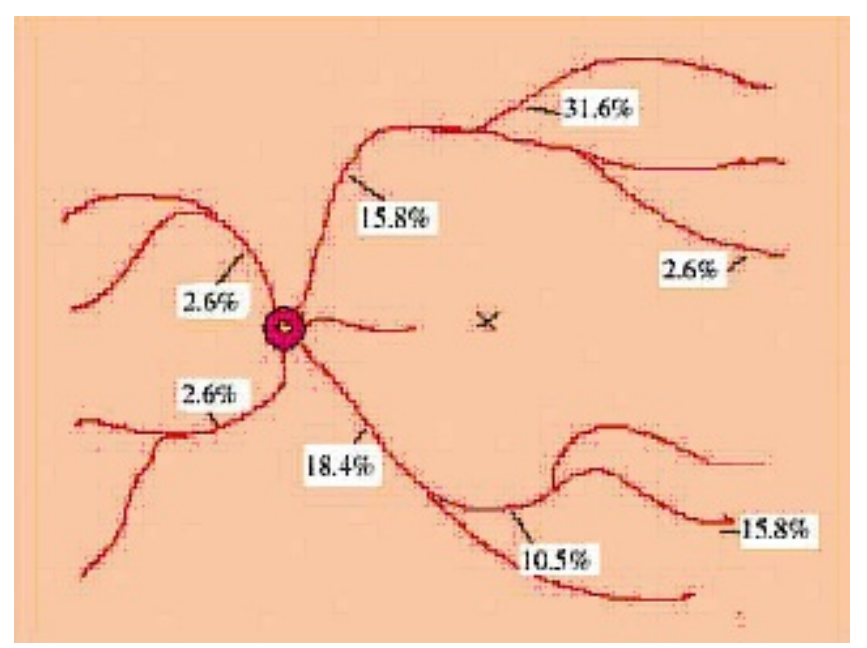

Figure 2. Common sites of retina artery macroaneurysm. ${ }^{2}$

*Correspondence: Dr. T S Oluleye, Retina and Vitreous Unit, Department of Ophthalmology, University College Hospital Ibadan • email: t_oluleye@yahoo.co.uk 


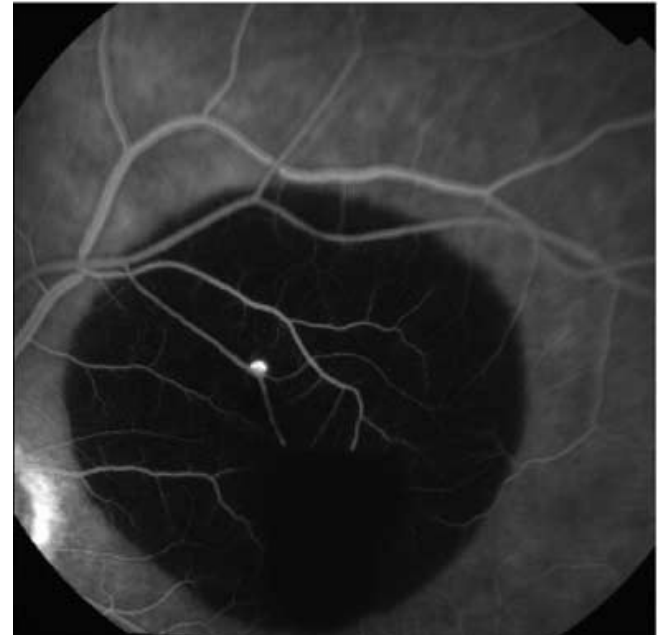

Figure 3. Fundus flourescein angiography demonstrating hyperflourescent macroaneurysm with hypoflourescent subretinal blood blocking choroidal fluorescence.

Predisposing factors: These include systemic hypertension, old age, female gender, artherosclerosis, lipid abnormalities, angiomatosis retina, Eale's disease, Leber's miliary aneurysms, retinal vascular occlusion (BRAO, BRVO), Coat's disease, hypertensive retinopathy and idiopathic polypoidal choroidal vasculopathy. ${ }^{3}$ The patient presented was elderly with uncontrolled hypertension.

Clinical presentation: Most cases are asymptomatic and are discovered during a routine eye exam. Sudden blurring of vision occurs when the macula is involved with exudation or when the aneurysm ruptures with associated vitreous or subretinal haemorrhage., ${ }^{3,4}$ Fundus flourescein angiography is an excellent tool in confirming the diagnosis as shown in figure 3 .

Differential diagnoses include retina telangiectasia, diabetic retinopathy, retina angiomas and other causes of vitreous, retina and subretinal haemorrhage.
Treatment: Conservative management and observation with control of systemic diseases such as hypertension and hyperlipidemia is sufficient in most cases. ${ }^{5}$ However, in eyes with persistent vitreous haemorrhage or macular oedema with lipid exudation, laser treatment is advocated ${ }^{6}$ (200-500 micron spot, for 0.2-0.5 sec light burn). Indirect laser delivery around the aneurism is shown to be effective with fewer side effects. ${ }^{6}$ Vitrectomy is recommended for macular haemorrhage and non-clearing vitreous haemorrhage. ${ }^{7}$ Most cases of macroaneurysm will resolve when managed conservatively. ${ }^{8}$

\section{REFERENCES}

1. Fichte C, Streeten BW, Friedman AH. A histopathologic study of retinal arterial aneurysms. Am J Ophthalmol. 1978; 85(4): 509-18.

2. RA Moosavi, KCS Fong and A Chopdar Retinal artery macroaneurysms:clinical and fluorescein angiographic features in 34 patients. Eye 2006; 20: 1011-1020.

3. Panton RW, Goldberg MF, Farber MD. Retinal arterial macroaneurysms: risk factors and natural history. $\mathrm{Br} J$ Ophthalmol. 1990; 74(10): 595-600.

4. Abdel-Khalek MN, Richardson J. Retinal macroaneurysm: Natural history and guidelines for treatment. $\mathrm{Br} J$ Ophthalmol. 1986; 70(1): 2-11.

5. Lavin MJ, Marsh RJ, Peart S, Rehman A. Retinal arterial macroaneurysms: a retrospective study of 40 patients. $\mathrm{Br}$ J Ophthalmol. 1987; 71(11): 817-25.

6. Nouhuys EV, Deutman AF. Argon laser treatment of retinal macroaneurysms. Int Ophthalmol 1980; 2(1): 45-53.

7. Zhao P, Hayashi H, Oshima K, Nakagawa N, Ohsato M. Vitrectomy for macular hemorrhage associated with retinal arterial macroaneurysm. Ophthalmology 2000; 107(3): 613-617.

8. Pam V, Babalola OE, Murdoch I. Macroaneurysm of the retinal artery in a Nigerian woman. Nigerian Journal of Ophthalmology 1993; 2(1): 62-64. 